\title{
Corrigendum
}

\section{Corrigendum to "miR-1-Mediated Induction of Cardiogenesis in Mesenchymal Stem Cells via Downregulation of Hes-1"}

\author{
Feng Huang, Liang Tang, Zhen-fei Fang, Xin-qun Hu, Jia-yi Pan, and Sheng-hua Zhou \\ Department of Cardiology, The Second Xiangya Hospital of Central South University, Hunan, Changsha 410011, China \\ Correspondence should be addressed to Sheng-hua Zhou; zhougqin@yeah.net \\ Received 7 December 2015; Accepted 24 May 2016 \\ Copyright (C) 2016 Feng Huang et al. This is an open access article distributed under the Creative Commons Attribution License, \\ which permits unrestricted use, distribution, and reproduction in any medium, provided the original work is properly cited.
}

In Figure 2(a) of the published article entitled "miR-1Mediated Induction of Cardiogenesis in Mesenchymal Stem Cells via Downregulation of Hes-1," [1] the authors admit to
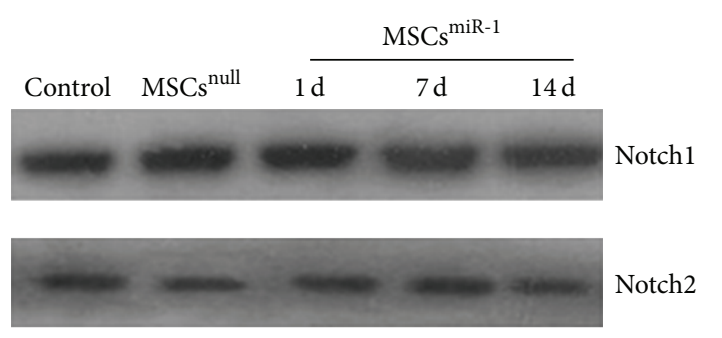

Notch2

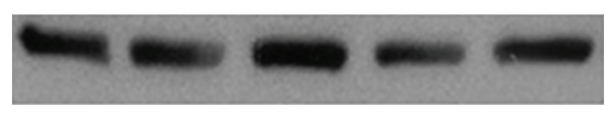

Notch4

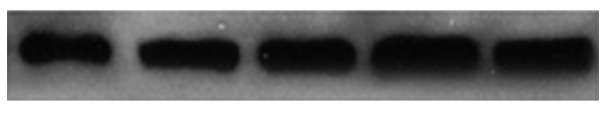

Dll-1

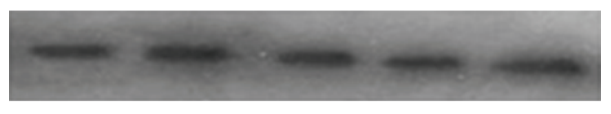

Dll-4

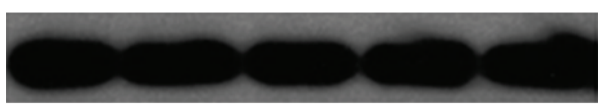

Jag-1

Hey-1 being careless in altering nonspecific belts, stains, or scratches in the Nkx2.5, cTnT, and CX43 panels. The original figures are presented here.
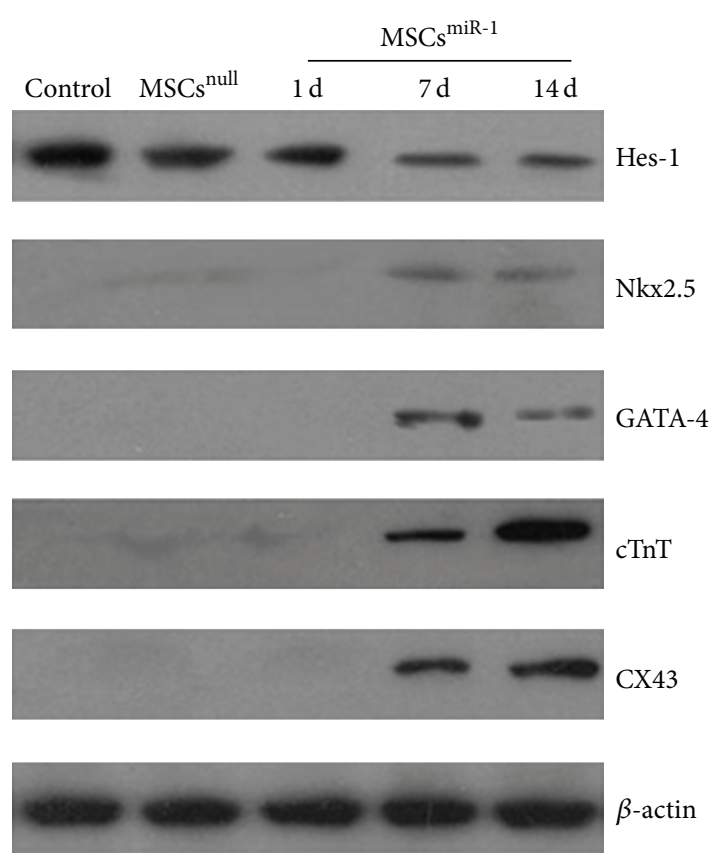

(a)

FIgURE 2: Continued. 


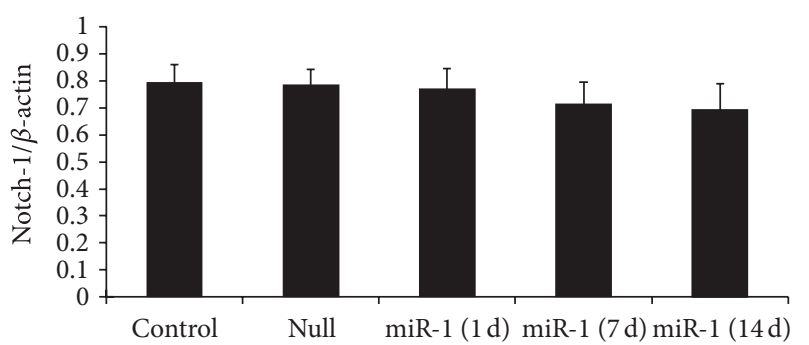

(b)

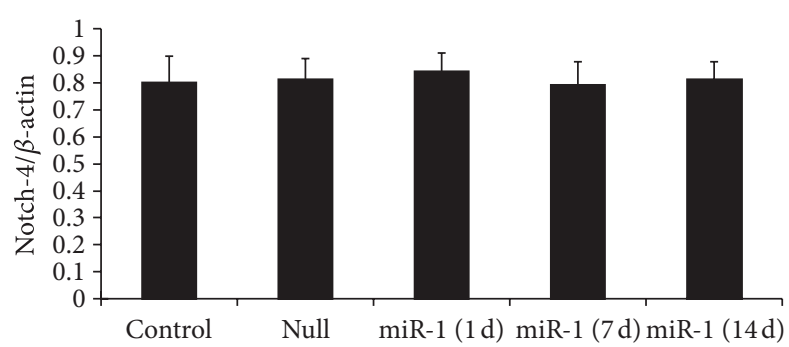

(d)

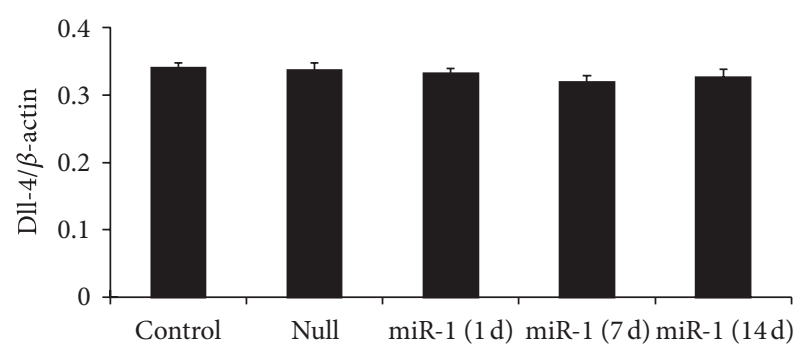

(f)

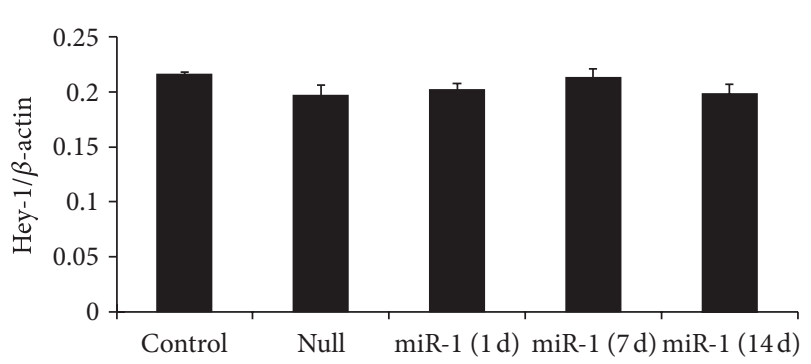

(h)

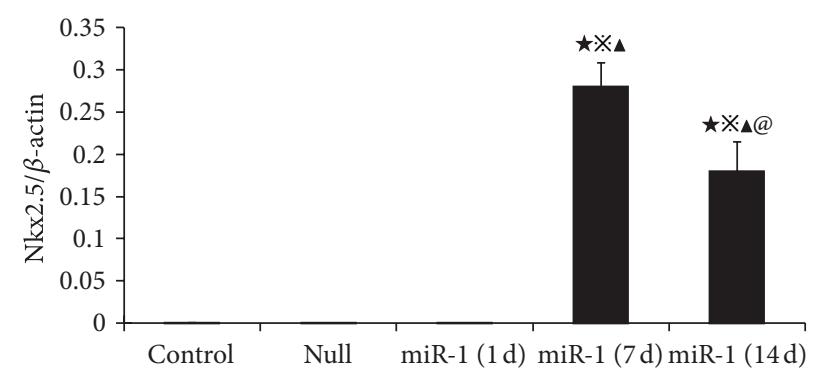

(j)

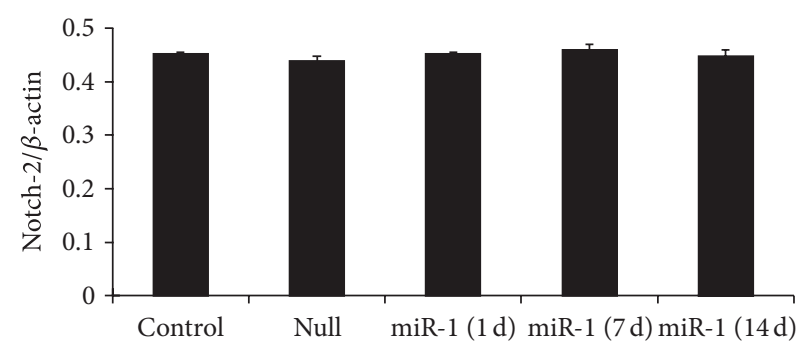

(c)

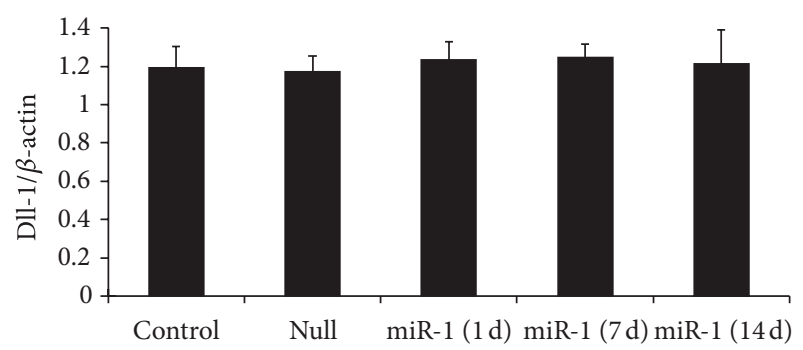

(e)

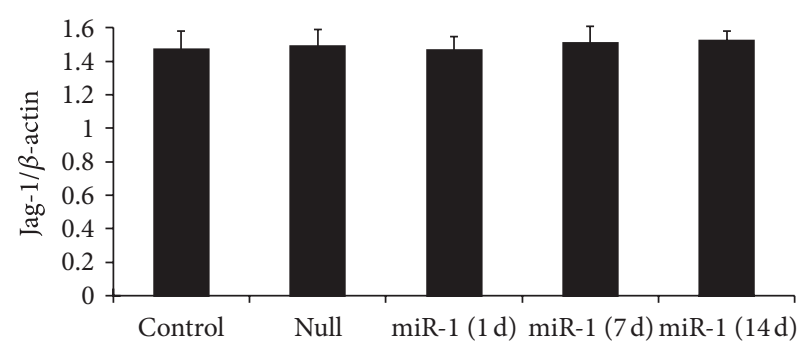

(g)

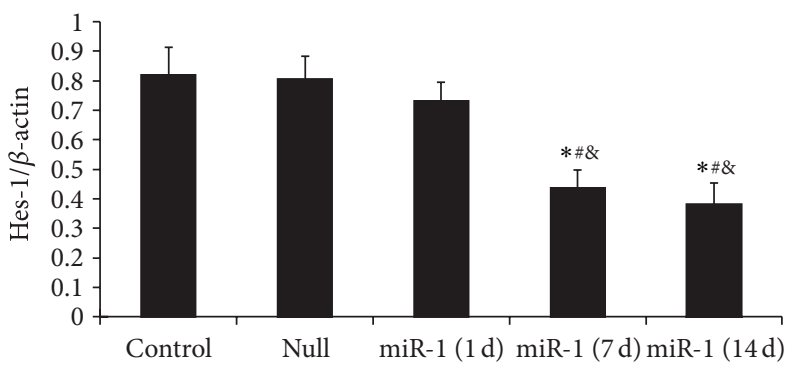

(i)

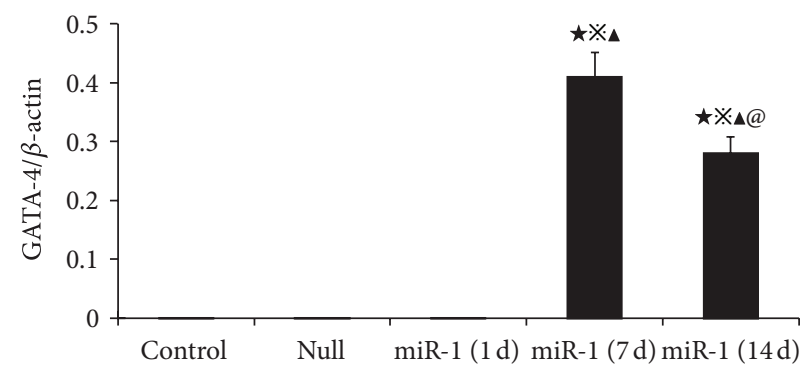

(k)

Figure 2: Continued. 


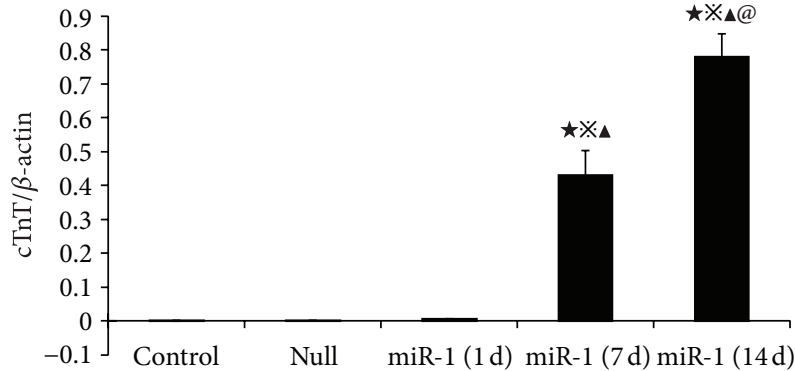

(l)

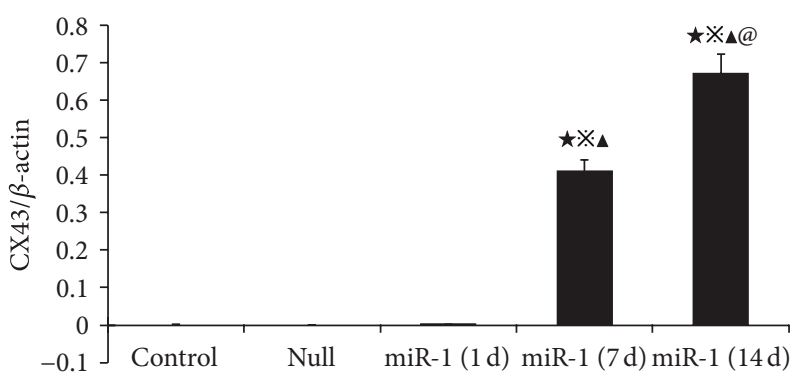

$(\mathrm{m})$

FIGURE 2: Western blot was performed for Notch signaling and cardiomyocyte-specific markers in MSCs, MSCs ${ }^{\text {null }}$, and MSCs ${ }^{\text {miR-1 }}$ (1 d, $7 \mathrm{~d}$, and 14 d). (a) Expression of Notch-1, Notch-2, Notch-4, Dll-1, Dll-4, Jag-1, Hes-1, and Hey-1 were detected on MSCs. Semiquantitative data showed that the ratio of optical density for Notch-1, Notch-2, Notch-4, Dll-1, Dll-4, Jag-1, and Hey-1 did not alter in MSCs ${ }^{\text {miR-1 }}$ on days 1, 7, and 14 (b)-(h). The expression of Hes-1 (i) in MSCs ${ }^{\text {miR-1 }}$ was decreased by days 7 and 14 . In MSCs ${ }^{\text {miR-1 }}$, the expression of Nkx2.5 (j) and GATA-4 (k) were detected on day 7 and decreased by day 14. $\mathrm{cTnT}(\mathrm{l})$ and CX43 (m) expression were detected on day 7 and significantly increased by day 14 (control = MSCs; null $=$ MSCs ${ }^{\text {null }}=$ MSCs infected with mock lentiviral vectors without miR-1; miR-1 $=$ MSCs ${ }^{\text {miR-1 }}=$ MSCs infected with miR-1 recombinant lentiviral vectors; compared to MSCs, ${ }^{*} P<0.05,{ }^{\star} P<0.01$; compared to MSCs ${ }^{\text {null }},{ }^{\#} P<0.05$, ${ }^{\star} P<0.01$; compared to $\operatorname{MSCs}^{\text {miR-1 }}(1 \mathrm{~d}),{ }^{\&} P<0.05,{ }^{\wedge} P<0.01$; compared to $\left.\operatorname{MSCs}^{\text {miR-1 }}(7 \mathrm{~d}),{ }^{\circledR} P<0.05\right)$.

\section{References}

[1] F. Huang, L. Tang, Z.-F. Fang, X.-Q. Hu, J.-Y. Pan, and S.H. Zhou, "miR-1-mediated induction of cardiogenesis in mesenchymal stem cells via downregulation of Hes-1," BioMed Research International, vol. 2013, Article ID 216286, 9 pages, 2013. 

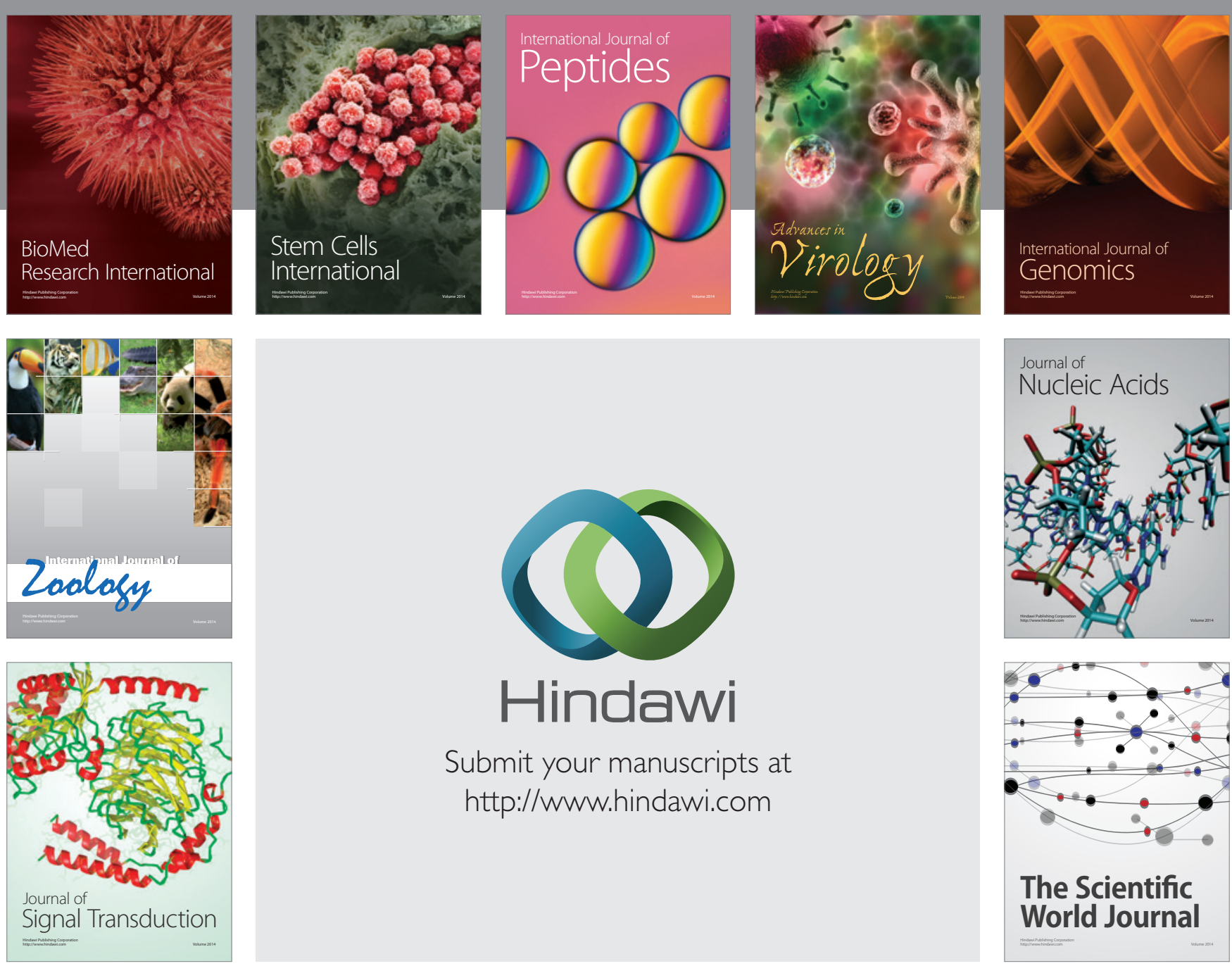

Submit your manuscripts at

http://www.hindawi.com
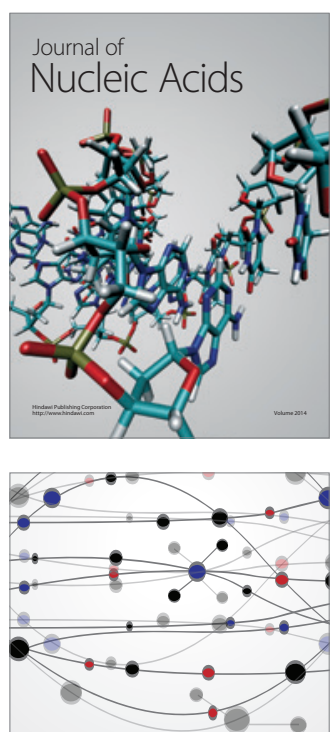

The Scientific World Journal
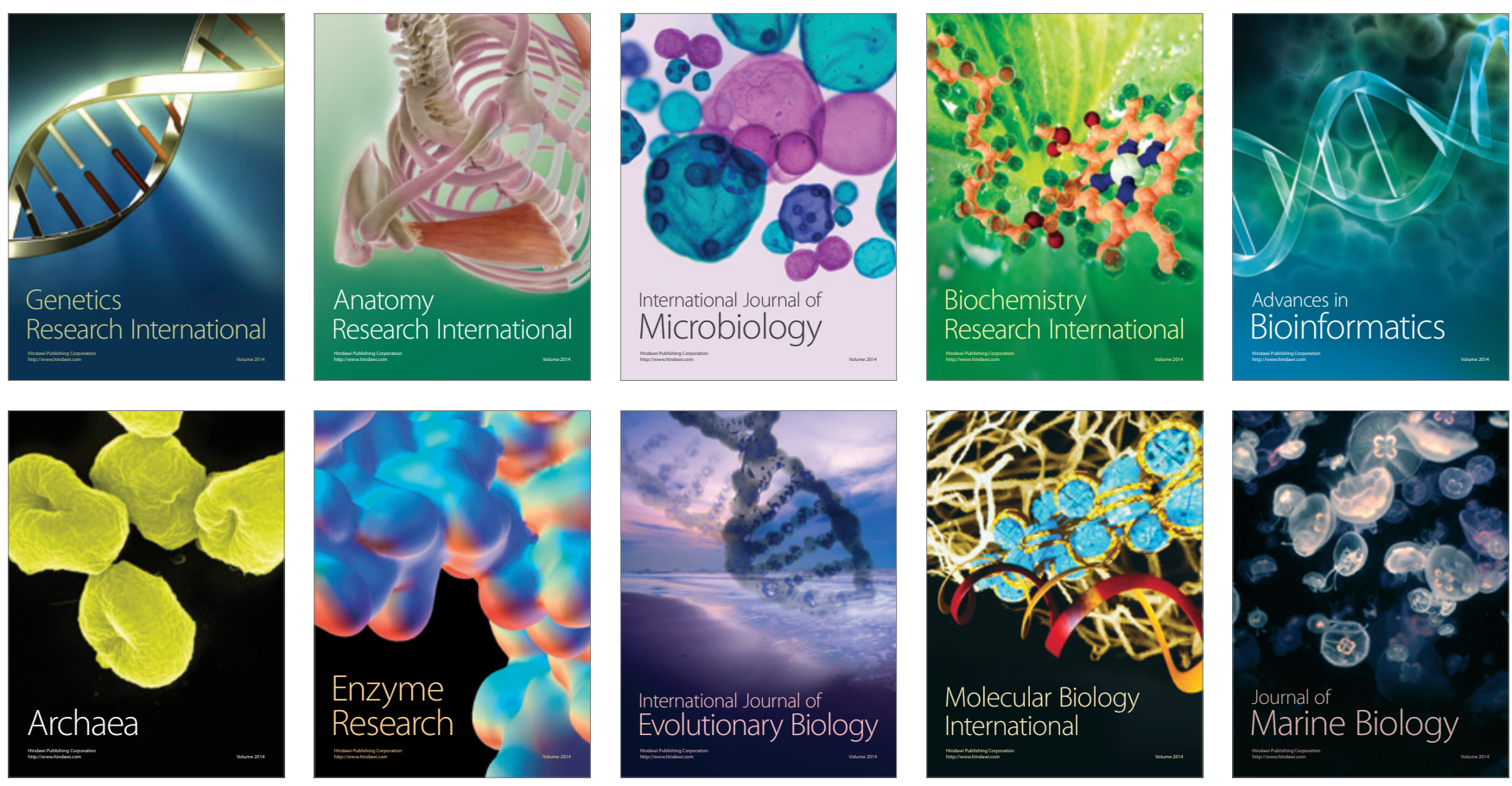